\title{
1 Reviews and Syntheses: Spatial and temporal patterns in metabolic
}

\section{2 fluxes inform potential for seagrass to locally mitigate ocean}

\section{3 acidification}

4 Kristy J. Kroeker ${ }^{1 *}$, Tye L. Kindinger ${ }^{1}$, Heidi K. Hirsh ${ }^{2}$, Melissa Ward ${ }^{3}$, Tessa M. Hill ${ }^{3,4}$,

5 Brittany M. Jellison ${ }^{3,6}$, David A. Koweek ${ }^{5}$, Sarah Lummis ${ }^{1}$, Emily B. Rivest ${ }^{3,7}$, George G.

6 Waldbusser $^{8}$, Brian Gaylord ${ }^{3,6}$

7

$8 \quad{ }^{1}$ Department of Ecology and Evolutionary Biology, University of California Santa Cruz, Santa

9 Cruz, CA, USA

$10 \quad{ }^{2}$ Department of Earth System Science, Stanford University, Stanford, CA, USA

$11{ }^{3}$ Bodega Marine Laboratory, University of California Davis, Bodega Bay, CA, USA

$12{ }^{4}$ Department of Earth and Planetary Sciences, University of California Davis, Davis, CA, USA

$13{ }^{5}$ Department of Global Ecology, Carnegie Institution for Science, Stanford, CA. Present address:

14 Ocean Visions, Inc. 225 Baker Street, Atlanta, GA, USA

$15{ }^{6}$ Department of Evolution and Ecology, University of California Davis, Davis, CA, USA

$16{ }^{7}$ Department of Biological Sciences, Virginia Institute of Marine Science, William \& Mary,

17 Gloucester Point, VA, USA

$18{ }^{8}$ College of Earth, Ocean and Atmospheric Sciences, Oregon State University, Corvallis, OR,

19 USA

$20 *$ correspondence to: Kristy J. Kroeker (kkroeker@ucsc.edu) 
22 Abstract: As global change continues to progress, there is a growing interest in assessing any local levers that could be used to manage the social and ecological impacts of rising $\mathrm{CO}_{2}$ concentrations. While habitat conservation and restoration have been widely recognized for their role in carbon storage and sequestration at a global scale, the potential for managers to use vegetated habitats to mitigate $\mathrm{CO}_{2}$ concentrations at local scales in marine ecosystems facing the accelerating threat of ocean acidification (OA) has only recently garnered attention. Early studies have shown that submerged aquatic vegetation, such as seagrass beds, can locally draw down $\mathrm{CO}_{2}$ and raise seawater $\mathrm{pH}$ in the water column through photosynthesis, but empirical studies of local OA mitigation are still quite limited. Here, we leverage the extensive body of literature on seagrass community metabolism to highlight key considerations for local OA management through seagrass conservation or restoration. In particular, we synthesize the results from 62 studies reporting in situ rates of seagrass gross primary productivity, respiration, and/or net community productivity to highlight spatial and temporal variability in carbon fluxes. We illustrate that daytime net community production is positive overall, and similar across seasons and geographies. Full-day net community production rates, which illustrate the potential cumulative effect of seagrass beds on seawater biogeochemistry integrated over day and night, were also positive overall, but were higher in summer months in both tropical and temperate ecosystems. Although our analyses suggest seagrass meadows are generally autotrophic, the modeled effects on seawater $\mathrm{pH}$ are relatively small in magnitude. In addition, we illustrate that periods when full-day net community production is highest could be associated with lower nighttime $\mathrm{pH}$ and increased diurnal variability in seawater $p \mathrm{CO}_{2} / \mathrm{pH}$. Finally, we highlight important areas for future research to inform the next steps for assessing the utility of this approach for management. 
1 Introduction

As carbon dioxide $\left(\mathrm{CO}_{2}\right)$ emissions continue to rise, there is an intense interest among managers and decision makers in developing local strategies to minimize the social and ecological costs of global change. While habitat restoration or conservation has been recognized for its utility in carbon storage and sequestration at a global scale in both terrestrial and aquatic systems (Canadell and Raupach 2008, Duarte et al. 2010, Agrawal et al. 2011, Mcleod et al. 2011, Nahlik and Fennessy 2016), the potential for using vegetated habitat to mitigate $\mathrm{CO}_{2}$ concentrations in the surrounding environment at very local scales has received far less attention. In marine ecosystems, however, increasing $\mathrm{CO}_{2}$ concentrations cause ocean acidification (OA), which poses a threat to species and ecosystems worldwide (Kroeker et al. 2010; 2013). Submerged aquatic vegetation can reduce $\mathrm{CO}_{2}$ concentrations in the water column through photosynthesis at a local scale (hereafter termed local OA mitigation) (Hendriks et al. 2014). Thus, conservation, restoration, and purposeful culturing of submerged aquatic vegetation have emerged as some of the few potential strategies for local OA mitigation for managers, providing possible benefits to other vulnerable species associated with these habitats (Washington State Blue Ribbon Panel on Ocean Acidification 2012, Chan et al. 2016, Nielsen et al. 2018).

64

Because both carbon sequestration and local OA mitigation will depend on the productivity of the vegetation, temporal variability in productivity may be especially important for managers considering local OA mitigation strategies. Carbon storage and sequestration in marine 
ecosystems is largely considered to be a cumulative process, whereas photosynthesis-based, local OA mitigation in the water column will necessarily be more intermittent or transient in time. In particular, variability in potential local OA mitigation can be expected on several different temporal scales. First, daytime and nighttime patterns in photosynthesis and respiration can cause substantial diurnal variability in seawater $\mathrm{pH}$ and saturation state (Hendriks et al. 2014, Pacella et al. 2018), such that potential local OA mitigation will vary on hourly timescales with daylight. Moreover, tidal cycles and local hydrodynamics may alter the impact these processes have on ambient water chemistry on hourly timescales as well (Cyronak et al. 2018, Koweek et al. 2018). Local hydrodynamics could significantly influence the time that a water mass experiences chemical alteration by a seagrass meadow, as well as the water depth through which light must penetrate to reach the seagrass canopy and the volume of water that must be modified, and therefore the magnitude of the change. On a longer timescale, seasonal patterns in temperature and light can also cause substantial seasonal variability in the biomass and productivity of submerged aquatic vegetation (Maher and Eyre 2011, Clavier et al. 2014, Ricart et al. 2021). Thus, the degree of any potential local OA mitigation may vary on seasonal or monthly timescales as well (Manzello et al. 2011, Unsworth et al. 2012, Cryonak et al. 2018, Saderne et al. 2019). This potential for temporal variability in photosynthesis-based, local OA mitigation has important implications for how the strategy might be used by managers, particularly with respect to whether potential OA mitigation aligns with windows of vulnerability for sensitive living resources or how variability is integrated through time by important species.

Seagrasses are productive marine macrophytes that are considered net autotrophic at the global scale (Duarte et al. 2010), suggesting that gross primary production (GPP, defined here as the 


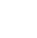

91

92

102 Scientists have been quantifying NCP in seagrass meadows for decades (Odum 1956), and

rate of oxygen production) should exceed respiration $(\mathrm{R}$, defined here as the rate of oxygen consumption, determined using incubations or measurements in the dark) on average. Assessing the utility of seagrass meadows for local OA mitigation, however, requires a better understanding of the spatial and temporal variability in GPP, R, and net community production (NCP, defined here as the GPP-R, or the net carbon flux, when both photosynthesis and respiration are accounted for). For example, diurnal variability in seawater carbonate chemistry could be more pronounced in geographies that support higher daytime GPP and nighttime R (Duarte et al. 2010). In addition, seasonal variability in NCP could be more pronounced in locations where there are larger fluctuations in light and other environmental drivers, such as high latitude or temperate ecosystems.

insight regarding the potential for temporal and spatial variability in carbon fluxes can be gained using this literature. In particular, understanding whether GPP, R, and NCP vary predictably across time and in different geographies can provide important, first order information about when and where local OA mitigation approaches might be effective, as well as insight into challenges that could arise in particular localities. Although potential local OA mitigation is caused by changes in the dissolved inorganic carbon (DIC) in seawater, which can be influenced by several other important biological and physical factors (Koweek et al. 2018, James et al. 2020), the relationship between $\mathrm{O}_{2}$ fluxes associated with seagrass metabolism and seawater DIC is roughly proportional (i.e., if $\mathrm{O}_{2}$ production goes up, DIC in seawater will go down). While empirical studies of changes in seawater DIC are currently limited, the comprehensive literature 


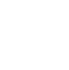

113 on seagrass community metabolism on $\mathrm{O}_{2}$ fluxes can provide important spatial and temporal

114 context for managers interested in carbon fluxes and the potential for local OA mitigation.

\title{
115
}

116 Here, we synthesize published studies of seagrass metabolism to characterize the variability in

117 carbon fluxes associated with GPP, R, and NCP across seasons and geographies. In recognition

118 of the substantial temporal diel variability in carbon fluxes associated with daytime NCP and

119 nighttime respiration, as well as the uncertainty in our understanding of how this temporal

120 variability is integrated by vulnerable marine organisms associated with seagrass beds, we focus

121 on both hourly rates of NCP taken during peak daylight hours and full-day NCP. Hourly

122 measurements of NCP collected during peak daylight hours can provide insight into the

123 maximum elevation of seawater $\mathrm{pH}$. Similarly, hourly measurements of respiration provide

124 insight into the potential maximum depression of nighttime $\mathrm{pH}$. In contrast, measurements of

125 NCP taken over longer time periods or that incorporate the full 24 hour cycle (full-day NCP)

126 provide insight into the cumulative effect of seagrass on seawater chemistry. In particular, we

127 tested: (1) If seasonal variability is present in daytime and full-day carbon fluxes, (2) If the

128 temporal variation in carbon fluxes varies among tropical and temperate geographies, and (3)

129 How much of the residual variation in carbon fluxes not accounted for by seasons or geography

130 can be attributed to variation in temperature and aboveground biomass of the seagrass

131 assemblage. To connect the metabolic measurements to seawater chemistry, we model potential

132 changes in bulk seawater $\mathrm{pH}$ based on the estimated carbon fluxes given variation in seawater

133 residence time and water depth.

\section{Methods}


136 We conducted a literature search for in situ measurements of seagrass community metabolism using the Web of Science. Search terms included [seagrass OR eelgrass OR submerged aquatic vegetation] AND [metabol* OR carbon/oxygen fluxes OR community prod* community resp* OR benthic incubation chambers OR primary prod* OR carbon* chemistry OR $p H]$. For each paper, we then searched the literature cited for more applicable studies, as well as any papers

141 listed in the Web of Science that cited the study in question. In addition, we searched the datasets used by Duarte et al. (2010) and Unsworth et al. (2012). Studies were included when either $\mathrm{O}_{2}$ or carbon fluxes of a seagrass-associated community were measured in situ. This included studies using a variety of methods, including incubation chambers, eddy correlation techniques, mass balance estimates, and isotope enrichment, among others. Studies were included that were

146 published prior to January 1, 2020.

Within a single study, regardless of the methods used, each deployment/set of measurements was included as a data point in the synthesis when deployments/measurements were repeated across different locations, months, or species. We collected measurements of GPP, R or NCP from each study using data reported in the text, tables, or graphs using software (Graph Click or Data

152 Thief), or provided by the authors by request. In addition, we recorded information on the 153 photosynthetic quotient (PQ) and respiratory quotient (RQ) values used to convert from $\mathrm{O}_{2}$ to

154 carbon, as well as other metadata associated with the study (e.g., species, location, temperature,

155 month the study was conducted, etc.). We classified each study as either tropical or temperate

156 based on the designation in the primary study and then classified the metabolic measurements as

157 either (a) hourly rates or (b) daily rates. This classification was defined by the reporting within 158 the studies (i.e., the primary authors either reported hourly or daily rates), but the difference in 


\section{(n)}

159 reporting was ostensibly due to differences in the length of the deployment used to measure

160 metabolism (e.g., $<4$ hour deployment $=$ an hourly rate, $\sim 12-24$ hour deployment $=$ a daily rate)

161 The shorter "hourly" deployments were usually taken during peak daylight hours, which we used

162 to infer the potential for any daytime local OA mitigation. In contrast, we use the daily rates to

163 infer the cumulative, full-day local OA mitigation potential of seagrass. It is important to note

164 that positive daily NCP (used to infer the full-day local OA mitigation potential) can still

165 encompass marked diel or diurnal variability in carbon fluxes that could prove deleterious to

166 seagrass associated species during transient periods of low $\mathrm{pH}$.

167

168 Although no studies included here measured changes in seawater DIC directly, several studies (N

$169=17)$ converted metabolism measurements based on oxygen consumption and production to

170 units of carbon. For studies that only reported metabolism in units of oxygen, we converted the

171 reported GPP, R, and NCP measurements to carbon using a PQ or RQ of 1 (Duarte et al. 2010).

172 We then converted all measurements to the same scale: either $\mathrm{mmol} \mathrm{C} / \mathrm{m}^{2} / \mathrm{hour}$ or $\mathrm{mmol}$

$173 \mathrm{C} / \mathrm{m}^{2} /$ day. Positive NCP values represent net autotrophy and carbon fluxes from the water

174 column to the seagrass tissue, and negative NCP values represent net heterotrophy and carbon

175 fluxes from the seagrass tissue to the water column.

176

177 To assess differences in estimates based on the methods used to measure metabolism, we plotted

178 the carbon fluxes as a function of study type. Based on these plots (Fig. S1), we decided to

179 perform separate analyses for studies that used the "mass balance" approach (Odum 1956) versus

180 other methods (e.g., incubations, eddy correlations). The studies using the mass balance

181 approach often do not differentiate between water column and benthic productivity, and as such, 
182 displayed a much higher range and magnitude of responses than those measured by other methods (see Methodological Analyses in Results below).

184

185 To assess the drivers of variability in carbon fluxes (hourly and daily rates of GPP, R and NCP),

186 we first assessed the collinearity in the primary drivers of interest: seawater temperature and

187 aboveground biomass for those studies reporting both variables. Because temperature and

188 aboveground biomass are correlated (temperature $\times$ geography: $\mathrm{P}=0.011$, Fig S2), we decided

189 to focus first on the effect of season, using month as a predictor variable, which ostensibly

190 encompasses some of the variability in both temperature and aboveground biomass (Figs S3 and

191 S4). Furthermore, the use of month as a predictor variable allowed us to include the maximum

192 number of studies in the analysis, since not all studies reported temperature and aboveground

193 biomass. To standardize months to seasons across the hemispheres, we used the numerical

194 notation for months in the northern hemisphere (i.e., January =1, etc.). For the southern

195 hemisphere, we subtracted 6 from the numerical notation and used the absolute value. In

196 addition, we tested for differences between seagrass communities in temperate and tropical

197 geographies based on the hypothesis that seagrass meadows in temperate geographies have

198 greater seasonality in light, temperature, and aboveground biomass, and thus, should have a more

199 pronounced seasonal fluctuation (Fig S3 and S4).

200

201 We then tested for effects of temperature and aboveground biomass on the residual variation of

202 the monthly models. Specifically, we first fit mixed-effects models of both hourly and daily rates

203 of GPP, R, and NCP using maximum likelihood with geography as a categorical factor (tropical

204 vs. temperate) and a linear and quadratic term for month as fixed effects, as well as the two-way 
205

206

207

208

209

210

211

212 We then used backwards model selection to determine the significance of fixed effects based on

214

215

216

217

218

219

220

221

222

223

224

225

226 interactions between geography and each term for month. We also included replicate nested in study as a random effect to account for non-independence arising from the inclusion of repeated measures from the same sites over time and measurements from multiple sites within a single study:

$$
\begin{gathered}
\text { metabolism } \sim \text { month }+ \text { month }^{2}+\text { geography }+ \text { month } \times \text { geography } \\
\left.+ \text { month }^{2} \times \text { geography }+1 \mid \text { study (replicate }\right)
\end{gathered}
$$
model estimates. We then performed two separate analyses using (1) environmental temperature and (2) aboveground biomass to assess any remaining variability in the residuals from the seasonal models. First, using just the subset of studies that either reported temperature or biomass, we fit the final seasonal models again using restricted maximum likelihood to obtain the conditioned residuals. Then, using these residuals, we fit linear models with geography as a categorical factor, plus a linear term for either temperature or aboveground biomass as well as the interaction between geography and temperature/biomass as fixed effects. We used backwards model selection, comparing nested models with a series of ANOVAs. Finally, we tested for net autotrophy $(\mathrm{NCP}>0)$ using a one-tailed t-test. All analyses were performed in $\mathrm{R}$ (version 3.6.2) (R Core Team 2019) with the following packages as needed: nlme (version 3.1.145) (Pinheiro et al. 2020), broom (version 0.7.3) (Robinson et al. 2020), and broom.mixed (version 0.2.6) (Bolker and Robinson 2020). 
(n)

227 To illustrate how water depth and residence time may mediate the effects of the carbon fluxes

228 associated with seagrass communities on bulk seawater $\mathrm{pH}$ for potential local OA mitigation, we

229 applied the range of hourly net carbon fluxes (NCP) covered in our synthesis to a simplified,

230 steady state box model developed by Koweek et al. (2018). We use the hourly rate rather than

231 the full-day rate because we recognize that the effects of seagrass on seawater carbonate

232 chemistry will be intermittent and fluctuate over the daylight hours. We modeled the change in

233 dissolved inorganic carbon as a function of NCP as

234

235

236

237

238

239

240

241

242

243

244

245

246

$247 \quad 3$ Results

\subsection{Description of the database}

249 Using our search criteria, we identified 62 published papers (spanning 1956 to 2020) that

250 reported in situ rates of seagrass community metabolism (Table S1). None of the studies directly

$$
\Delta D I C=\frac{L}{\bar{u} \rho h} \times \mathrm{NCP}
$$

where $L=$ the box length $(\mathrm{m}), \bar{u}=$ mean water velocity $\left(\mathrm{m} \mathrm{s}^{-1}\right), \rho=$ is the seawater density $(\mathrm{kg}$ $\left.\mathrm{m}^{3}\right)$, and $h=$ water depth $(\mathrm{m})$, Because of the familiarity among managers and decision makers with seawater $\mathrm{pH}$, we then converted the delta DIC to $\mathrm{pH}$, assuming a relevant, temperate coastal ocean condition (e.g., total alkalinity $=2300 \mu \mathrm{mol} / \mathrm{kg}$, temperature $=15^{\circ} \mathrm{C}$, and salinity $=35$ ppm). We then plotted the change in $\mathrm{pH}$ as a function of hourly daytime carbon fluxes (i.e., hourly NCP) for two different water depths $(0.5$ and $2 \mathrm{~m})$ and three different water residence times $(L / \underline{u}=15$ minutes, 60 minutes, and 4 hours $)$ at each water depth. We selected four hours as the maximum duration for the model for two reasons: seagrass beds are rarely extensive enough for water to remain over seagrass for more than a few hours, and longer residence times would tend to overlap with lower-light conditions when the hourly NCP does not apply.

\footnotetext{
reported in situ rates of seagrass community metabolism (Table S1). None of the studies directly
} 
https://doi.org/10.5194/bg-2021-137

Preprint. Discussion started: 28 May 2021

(C) Author(s) 2021. CC BY 4.0 License.

251 measured changes in DIC, but 17 of the 62 studies reported metabolic measurements in units of

252 carbon. The complete set of studies spanned temperate and tropical ecosystems. The inclusion of

25336 temperate studies and an additional 15 tropical studies significantly expanded the scope of

254 inference beyond previous reviews (Duarte et al. 2010; Unsworth et al. 2012). Many studies

255 occurred in the Western Atlantic and Mediterranean (Fig. 1), and there were no studies from the

256 North Pacific. Most studies measured seagrass metabolism during the spring and summer

257 months, while fewer studies measured the metabolism in fall and winter conditions (Fig. 1).

258 Environmental temperature was highest during late summer/early fall months and was higher

259 overall in tropical biomes (Fig S3). Aboveground biomass was highest during summer months

260 and higher in the temperate geographies (Fig S4). 
https://doi.org/10.5194/bg-2021-137

Preprint. Discussion started: 28 May 2021

(c) Author(s) 2021. CC BY 4.0 License.

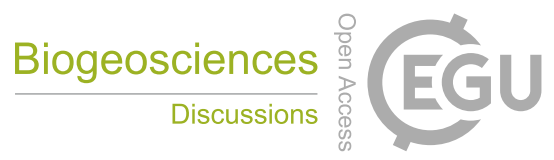

(c) (1)
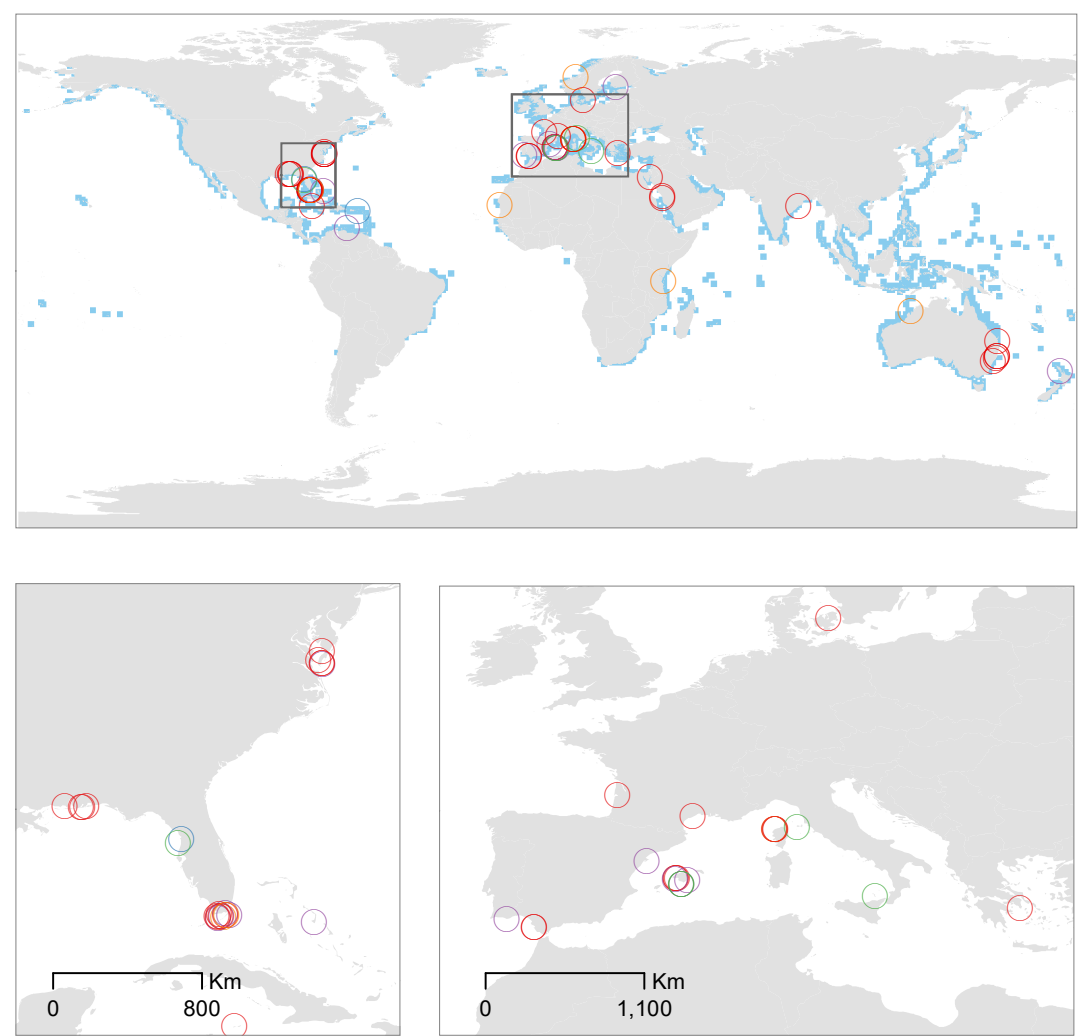

Sampling Season

Winter
Spring
Summer
Fall
Multiple Seasons

263 Figure 1. Studies included in the analyses span temperate to tropical ecosystems, with many

264 studies occurring in the Western Atlantic and Mediterranean. Most studies measured seagrass

265 metabolism during the spring and summer months, while fewer studies measured the metabolism

266 in fall and winter conditions. Blue pixels represent the distribution of seagrasses from UNEP-

267 WCMC and Short (2018). 
269

270

271

272

273

274

275

276

277

278

279

280

281

282

283

284

285

286

287

288

289

290

291

\subsection{Methodological analyses}

Our results illustrate greater variability in the ranges of response observed using the "mass balance" method, which extend in magnitude beyond those observed using other methods for measuring both GPP and R (Fig. S1 a-f). This greater variability does not appear to be driven by timing of the measurements as the "mass balance" method produced metabolic measurements of higher variability or magnitude across seasons (Fig S1 g-1). Measurements taken using incubations, eddy correlation methods, and water column measurements of $\mathrm{pH}$ using in situ sensors and an acoustic doppler velocimeter (or other instrument capable of measuring flow) are generally of similar magnitude and variation.

\subsection{Spatial and temporal patterns in carbon fluxes}

\subsubsection{Daytime carbon fluxes}

Measurements of hourly carbon fluxes $(\mathrm{N}=83$ for $\mathrm{NCP})$, typically obtained from shorter duration deployments conducted during peak sunlight hours, reveal differences in seasonal patterns of GPP and respiration. Both GPP and R peak during summer months across both ecosystems (Fig 2a-b). Despite higher biomass in temperate systems during summer months (Fig S4), we do not detect a statistical difference in the seasonal patterns among GPP in temperate and tropical ecosystems (Table 1). This result is highly influenced by two studies in tropical geographies (Morgan and Kitting 1984, Herbert and Fourqurean 2008); when these studies are not included, summertime GPP is higher in temperate geographies than in tropical geographies (Fig S5). Similarly, R peaks in summer months in both temperate and tropical ecosystems, and we detect a sharper increase and a higher seasonal peak in $\mathrm{R}$ in temperate ecosystems (Fig 2b; Table 1). The seasonal peaks in GPP and R effectively cancel each other out, resulting in no statistically 
292 detectable difference in hourly NCP rates across seasons (Fig 2c). Although the net hourly

293 carbon flux associated with NCP does not vary seasonally, the mean net hourly carbon flux from

294 the seawater to the seagrass is positive (mean hourly $\mathrm{NCP}=5.32+/-5.93 \mathrm{SD} \mathrm{mmol} \mathrm{C} / \mathrm{m}^{2} / \mathrm{hour}$ ),

295 indicating a net draw down of seawater DIC during peak daylight hours regardless of geography

296 (one-tailed t-test: $\mathrm{t}_{82}=8.18, \mathrm{P}<0.001$ ). Ninety-three percent of the 83 measurements were net

297 autotrophic.

(a) GPP

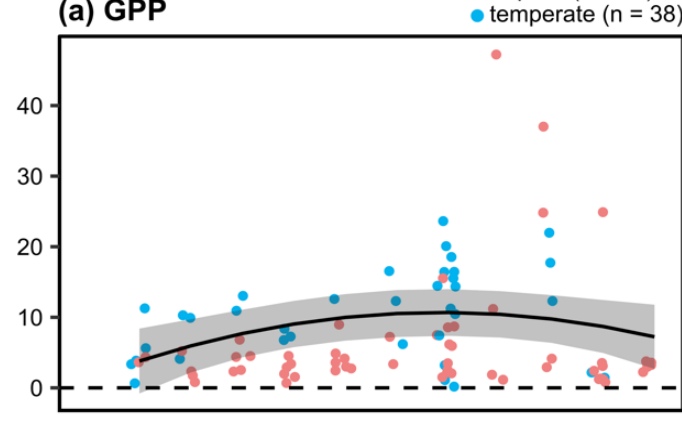

(b) $\mathbf{R}$

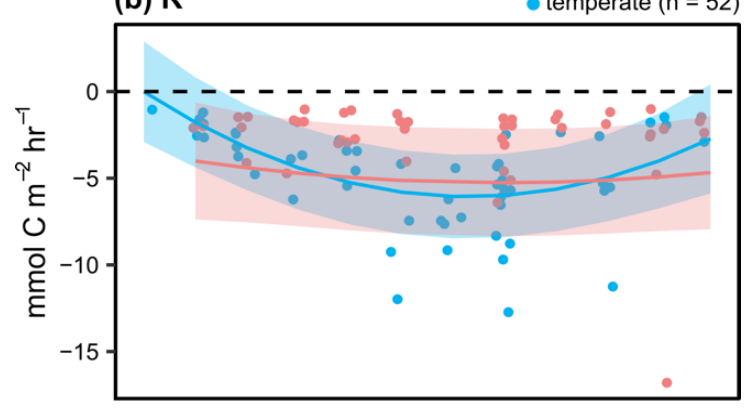

(c) NCP

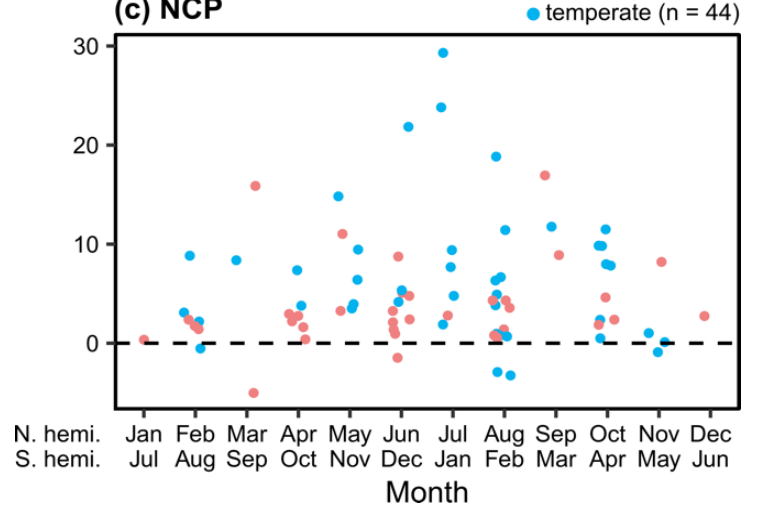

Figure 2. Hourly rates for $\mathrm{C}$ fluxes $\left(\mathrm{mmol}^{-1} \mathrm{~m}^{2-}\right.$ ${ }^{1}$ hour-1) associated with seagrass communities as a function of time, with GPP measurements taken during peak sunlight hours $(\sim 10$ am to 2 pm local time). Studies performed in temperate versus tropical ecosystems are illustrated by color $($ blue $=$ temperate, red $=$ tropical $)$, and significance $(\mathrm{p}<0.05)$ is denoted by a fit line with a quadratic term and $95 \% \mathrm{CI}$. The colors of the lines denote significant differences between tropical and temperate systems in GPP and R, while a black line denotes a significant relationship but no difference between temperate and tropical geographies. 
https://doi.org/10.5194/bg-2021-137

Preprint. Discussion started: 28 May 2021

(c) Author(s) 2021. CC BY 4.0 License.

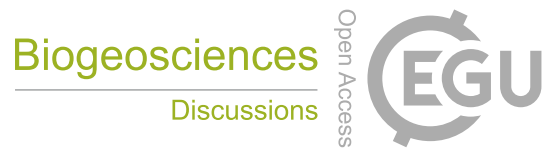

317 Table 1. Statistics for linear mixed effects models of hourly rates of carbon fluxes. Terms in grey

318 were removed from the final model using backward model selection.

319

\begin{tabular}{|c|c|c|c|c|c|}
\hline Response & $\begin{array}{l}\text { Outliers } \\
\text { removed }\end{array}$ & Fixed effect & df & L-ratio & p-value \\
\hline \multirow[t]{10}{*}{ GPP $\left(\mathrm{mmol} \mathrm{C} / \mathrm{m}^{2} / \mathrm{hr}\right)$} & 0 & month & & & \\
\hline & & month $^{2}$ & 5 & 6.76905 & 0.0093 \\
\hline & & geography & 6 & 0.73356 & 0.3917 \\
\hline & & month $\times$ geography & 7 & 0.00066 & 0.9795 \\
\hline & & month $^{2} \times$ geography & 8 & 0.32073 & 0.5712 \\
\hline & 4 & month & & & \\
\hline & & month $^{2}$ & 7 & 13.7499 & 0.0002 \\
\hline & & geography & & & \\
\hline & & month $\times$ geography & 8 & 4.60594 & 0.0319 \\
\hline & & month $^{2} \times$ geography & 8 & 3.5689 & 0.0589 \\
\hline \multirow[t]{10}{*}{$\mathrm{R}\left(\mathrm{mmol} \mathrm{C} / \mathrm{m}^{2} / \mathrm{hr}\right)$} & 0 & month & & & \\
\hline & & month $^{2}$ & & & \\
\hline & & geography & & & \\
\hline & & month $\times$ geography & 8 & 5.98346 & 0.0144 \\
\hline & & month $^{2} \times$ geography & 8 & 5.72857 & 0.0167 \\
\hline & 1 & month & & & \\
\hline & & month ${ }^{2}$ & & & \\
\hline & & geography & & & \\
\hline & & month $\times$ geography & 8 & 9.23633 & 0.0024 \\
\hline & & month $^{2} \times$ geography & 8 & 8.73371 & 0.0031 \\
\hline \multirow[t]{5}{*}{$\mathrm{NCP}\left(\mathrm{mmol} \mathrm{C} / \mathrm{m}^{2} / \mathrm{hr}\right)$} & 0 & month & 4 & 0.04176 & 0.8381 \\
\hline & & month $^{2}$ & 5 & 2.65064 & 0.1035 \\
\hline & & geography & 6 & 0.04703 & 0.8283 \\
\hline & & month $\times$ geography & 7 & 3.41018 & 0.0648 \\
\hline & & month $^{2} \times$ geography & 8 & 1.09949 & 0.2944 \\
\hline
\end{tabular}

320

321

322

323

324 
325

326

327

328

\subsubsection{Full-day carbon fluxes}

We found 164 measurements/deployments that reported full-day NCP using methods that span a wider range of photoperiods and environmental conditions, and thus provide insight into the potential for full-day local OA mitigation. Based on the accompanying daily rates of GPP and R, there is evidence of a seasonal cycle in carbon fluxes to and from the water column associated with seagrass metabolism (Fig. 3a-b). The seasonal fluctuation differed statistically between temperate and tropical geographies, with a sharper slope in the seasonal fluctuation among the tropical studies (Fig 2a). We did not detect a difference in R between geographies. In general, the seasonal fluctuation in GPP exceeds the seasonal fluctuation in respiration in both geographies, resulting in higher daily net carbon flux from the seawater to the seagrass associated with NCP in summer months (Fig. 3c). The seasonal fluctuation in NCP was greater among the tropical studies than the temperate studies (Table 2). The mean NCP for tropical geographies was 62.5 (+/- 62.4 SD) $\mathrm{mmol} \mathrm{C} / \mathrm{m}^{2} /$ day, with $84 \%$ of the 77 total reported measurements being autotrophic. The mean NCP for temperate geographies was $28.8(+/-79.0) \mathrm{mmol} \mathrm{C} / \mathrm{m}^{2} / \mathrm{day}$, with $68 \%$ of the 187 total reported measurements being autotrophic. Overall, the seagrass meadows in both geographies were net autotrophic (one-tailed t-test: tropical $t_{76}=8.78, \mathrm{P}<0.001$; temperate $\left.t_{186}=4.98, \mathrm{P}<0.001\right)$. Despite these overall trends, there are several individual studies that reported net heterotrophy and net carbon fluxes to the water column, even during summer months. 

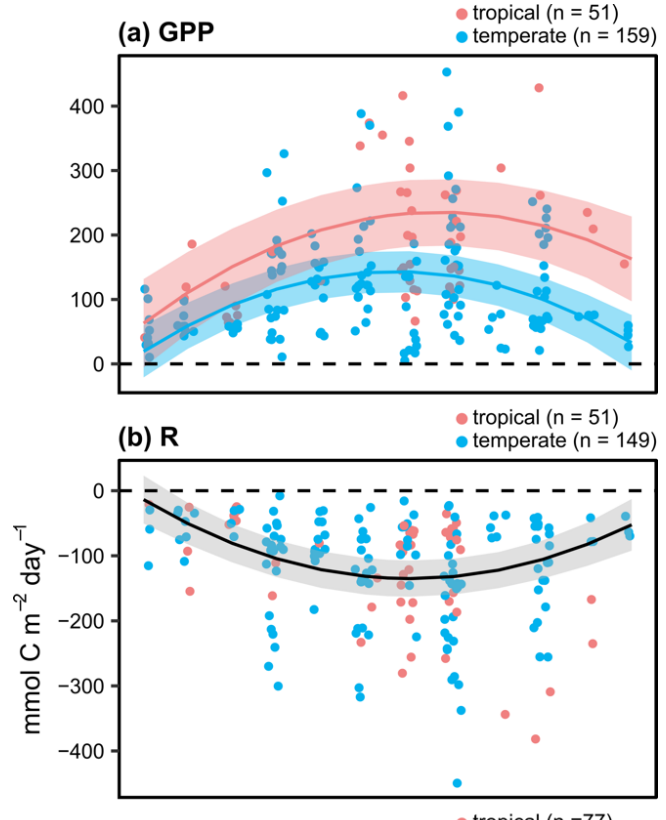

(c) NCP

- tropical $(n=77)$

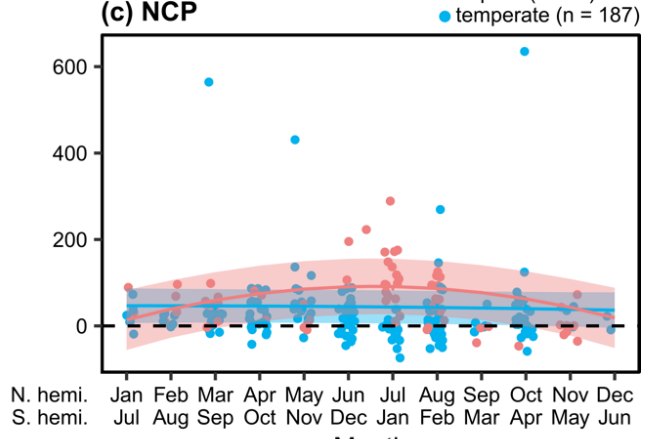

345 Figure 3. Daily rates for $\mathrm{C}$ fluxes $\left(\mathrm{mmol}^{-1} \mathrm{~m}^{2-1} \mathrm{day}^{-1}\right)$ associated with seagrass communities as a function of time. Studies performed in temperate versus tropical ecosystems are illustrated by color $($ blue $=$ temperate, red $=$ tropical $)$, and significance $(\mathrm{p}<0.05)$ is denoted by a fit line with a quadratic term and $95 \% \mathrm{CI}$. The colors of the lines denote significant differences between tropical and temperate systems. 
https://doi.org/10.5194/bg-2021-137

Preprint. Discussion started: 28 May 2021

(C) Author(s) 2021. CC BY 4.0 License.

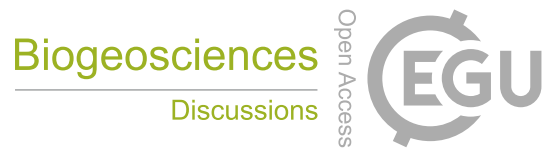

(c) (i)

352 Table 2. Statistics for linear mixed effects models of daily rates of carbon fluxes. Terms in grey

353 were removed from the final model using backward model selection.

\begin{tabular}{|c|c|c|c|c|}
\hline Response & Fixed effect & df & L-ratio & p-value \\
\hline \multirow[t]{5}{*}{ GPP (mmol C/m²/day) } & month & & & \\
\hline & month $^{2}$ & 7 & 54.5932 & $<0.0001$ \\
\hline & geography & & & \\
\hline & month $\times$ geography & 7 & 4.28394 & 0.0385 \\
\hline & month $^{2} \times$ geography & 8 & 0.05199 & 0.8196 \\
\hline \multirow[t]{5}{*}{$\mathrm{R}\left(\mathrm{mmol} \mathrm{C} / \mathrm{m}^{2} /\right.$ day $)$} & month & & & \\
\hline & month $^{2}$ & 5 & 40.5399 & $<0.0001$ \\
\hline & geography & 6 & 2.7621 & 0.0965 \\
\hline & month $\times$ geography & 7 & 2.2282 & 0.1355 \\
\hline & month $^{2} \times$ geography & 8 & 2.04071 & 0.1531 \\
\hline \multirow[t]{5}{*}{$\mathrm{NCP}\left(\mathrm{mmol} \mathrm{C} / \mathrm{m}^{2} /\right.$ day $)$} & month & & & \\
\hline & month $^{2}$ & & & \\
\hline & geography & & & \\
\hline & month $\times$ geography & 8 & 16.9111 & $<0.0001$ \\
\hline & month $^{2} \times$ geography & 8 & 15.1501 & $<0.0001$ \\
\hline
\end{tabular}

355

356

357

358

359

360

361

362

363

364 
https://doi.org/10.5194/bg-2021-137

Preprint. Discussion started: 28 May 2021

(C) Author(s) 2021. CC BY 4.0 License.

366 Within seasons, there is still marked variation in GPP and respiration (Fig. 2-3). Using the subset

367 of studies that report environmental temperature $(\mathrm{N}=28)$, we found that temperature did not

368 explain the residual variability in any metric besides hourly GPP (Fig. 4; Table 3), suggesting the

369 seasonal models may generally account for hypothesized temperature effects. As noted,

370 temperature explained some of the residual variability from the seasonal models of hourly GPP,

371 with the effect differing among tropical and temperate geographies (Fig S6; Hourly GPP

372 Geography $x$ Temperature: $\left.F_{42}=10.83, \mathrm{P}=0.001\right)$. Among studies reporting aboveground

373 biomass $(\mathrm{N}=23)$, biomass explains some of the residual variability in daily $\mathrm{NCP}$, although the

374 effect depends on geography as well (Fig 5; Table 3). Aboveground biomass also explains some

375 of the residual variability in the seasonal models of hourly GPP, respiration, and NCP, and the

376 effect of biomass on hourly GPP also depended on the geography (Fig. S7; Table 3). 


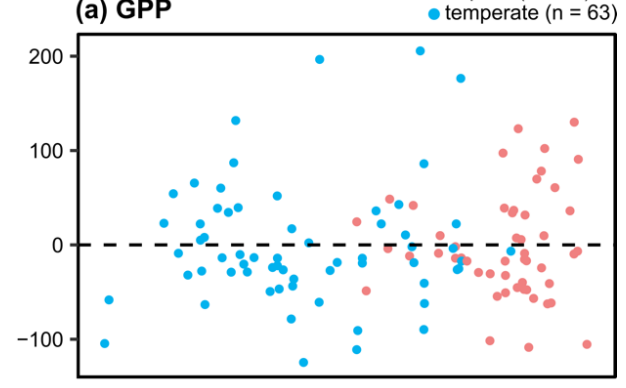

(b) $\mathrm{R}$

tropical $(n=51)$
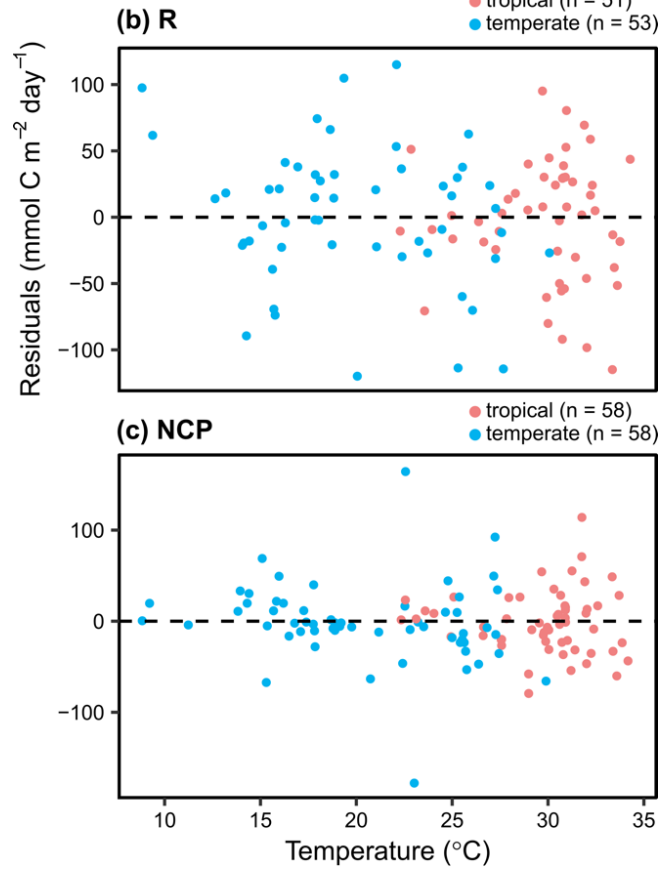

378 Figure 4. Conditioned residuals of the daily rates of $\mathrm{C}$ fluxes $\left(\mathrm{mmol}^{-1} \mathrm{~m}^{2-1} \mathrm{day}^{-1}\right)$ from a seasonal

379 model as a function of temperature. Studies performed in temperate versus tropical ecosystems

380 are illustrated by color (blue $=$ temperate, red $=$ tropical). None of the relationships are

381 statistically significant. 

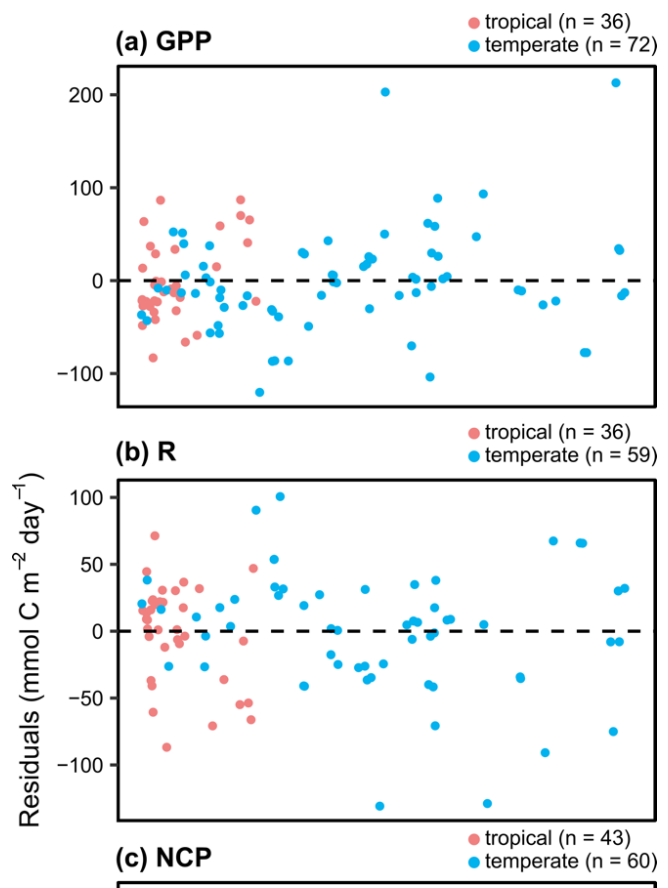

384 Figure 5. Conditioned residuals of the daily rates for seagrass $\mathrm{C}$ fluxes $\left(\mathrm{mmol}^{-1} \mathrm{~m}^{2-1} \mathrm{day}^{-1}\right)$ from a 385 seasonal model as a function of aboveground biomass measured in the field during metabolism measurements. Studies performed in temperate versus tropical ecosystems are illustrated by color

387 (blue $=$ temperate, red $=$ tropical). Significance is denoted by a fit line and $95 \% \mathrm{CI}$. 
https://doi.org/10.5194/bg-2021-137

Preprint. Discussion started: 28 May 2021

(c) Author(s) 2021. CC BY 4.0 License.

391 Table 3. Statistics for mixed effects models of the residuals of the hourly metabolic rates as a

392 function of biomass or temperature and geography and the interactions.

\begin{tabular}{|c|c|c|c|c|c|c|}
\hline Response & Fixed effect & $\mathbf{d f}_{\text {res }}$ & SS $_{\text {res }}$ & SS & $\mathbf{F}$ & p-value \\
\hline \multirow[t]{3}{*}{ GPP (mmol C/m²/hr) } & biomass & & & & & \\
\hline & geography & & & & & \\
\hline & biomass $\times$ geography & 33 & 2806.1 & -1081.7 & 20.074 & $<0.0001$ \\
\hline \multirow[t]{3}{*}{$\mathrm{R}\left(\mathrm{mmol} \mathrm{C} / \mathrm{m}^{2} / \mathrm{hr}\right)$} & biomass & 30 & 175.9 & -20.68 & 3.864 & 0.059 \\
\hline & geography & 30 & 161.9 & -6.681 & 1.248 & 0.273 \\
\hline & biomass $\times$ geography & 29 & 155.3 & -1.505 & 0.274 & 0.605 \\
\hline \multirow[t]{3}{*}{$\mathrm{NCP}\left(\mathrm{mmol} \mathrm{C} / \mathrm{m}^{2} / \mathrm{hr}\right)$} & biomass & 38 & 1640.2 & -186.1 & 4.736 & 0.036 \\
\hline & geography & 38 & 1721.4 & -267.4 & 6.803 & 0.013 \\
\hline & biomass $\times$ geography & 37 & 1454.1 & -140.3 & 3.844 & 0.058 \\
\hline \multirow[t]{3}{*}{ GPP $\left(\mathrm{mmol} \mathrm{C} / \mathrm{m}^{2} / \mathrm{hr}\right)$} & temp & & & & & \\
\hline & geography & & & & & \\
\hline & temp $\times$ geography & 42 & 375.4 & -71.84 & 9.704 & 0.003 \\
\hline \multirow[t]{3}{*}{$\mathrm{R}\left(\mathrm{mmol} \mathrm{C} / \mathrm{m}^{2} / \mathrm{hr}\right)$} & temp & 61 & 221.7 & -0.930 & 0.253 & 0.617 \\
\hline & geography & 60 & 220.8 & -0.104 & 0.028 & 0.868 \\
\hline & temp $\times$ geography & 59 & 220.7 & -0.004 & 0.001 & 0.976 \\
\hline \multirow[t]{3}{*}{$\mathrm{NCP}\left(\mathrm{mmol} \mathrm{C} / \mathrm{m}^{2} / \mathrm{hr}\right)$} & temp & 46 & 1453.0 & -41.82 & 1.334 & 0.254 \\
\hline & geography & 47 & 2141.0 & -688.0 & 21.78 & $<0.0001$ \\
\hline & temp $\times$ geography & 45 & 1411.2 & -12.30 & 0.387 & 0.537 \\
\hline
\end{tabular}

393

394

395

396

397

398

399

400

401 
https://doi.org/10.5194/bg-2021-137

Preprint. Discussion started: 28 May 2021

(C) Author(s) 2021. CC BY 4.0 License.

403 The steady state box model illustrates that the largest potential change in seawater $\mathrm{pH}$ occurs

404 when NCP is highest and the water depth and residence time are lowest (Fig. 6). Using the mean

405 hourly NCP from our analysis ( $\sim 5.32 \mathrm{mmol} \mathrm{C} / \mathrm{m}^{2} /$ hour; Fig. $\left.2 \mathrm{C}\right)$, the potential change in

406 seawater $\mathrm{pH}$ in a seagrass meadow that meets the assumptions of the box model (e.g., $\Delta \mathrm{O}_{2}: \Delta \mathrm{DIC}$

$407=1$ ) in a low flow environment at low tide (i.e., $0.5 \mathrm{~m}$ water depth) ranges from $0.006-0.085 \mathrm{pH}$

408 units for a residence time from 15 minutes to 4 hours. At the modeled higher tide (i.e., $2 \mathrm{~m}$ water

409 depth), the potential changes in seawater $\mathrm{pH}$ for the same NCP range from $0.001-0.022 \mathrm{pH}$ units

410 for the same residence times (15 minutes to 4 hours).

411

412

413

414 
https://doi.org/10.5194/bg-2021-137

Preprint. Discussion started: 28 May 2021

(c) Author(s) 2021. CC BY 4.0 License.
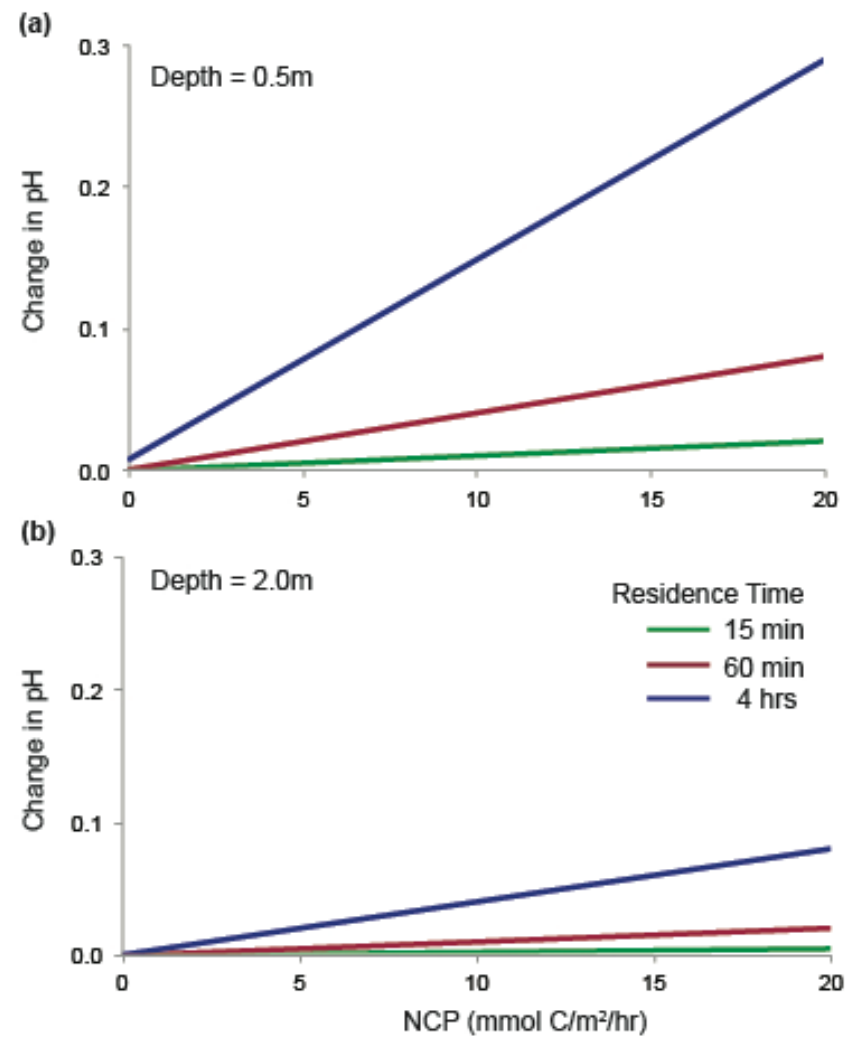

416 Figure 6. Results from a steady state box model illustrating the change in seawater $\mathrm{pH}$ as a

417 function of NCP at (A) $0.5 \mathrm{~m}$ water depth and (B) $2 \mathrm{~m}$ water depth. The change in seawater $\mathrm{pH}$ is

418 illustrated for a series of different residence times $(\mathrm{L} / \mathrm{u})$. Both panels are modeled at the same

419 temperature $\left(15^{\circ} \mathrm{C}\right)$, total alkalinity $(2300 \mu \mathrm{mol} / \mathrm{kg})$, and salinity $(35 \mathrm{ppm})$, with an incoming

420 DIC of $2100 \mu \mathrm{mol} / \mathrm{kg}$.

421

422

423

424

425 
426

427

428

429

430

431

432

433

434

435

436

437

438

439

440

441

442

443

444

445

446

447

\section{Discussion}

\subsection{Spatial and temporal variability in seagrass metabolism}

Here, we report that the NCP of seagrass beds during daylight hours is positive and similar across seasons and geographies (Fig 2C). This is ostensibly due to GPP generally exceeding R during daylight and the seasonal fluctuations in hourly rates of GPP and R balancing each other out. If $\mathrm{O}_{2}$ fluxes translate proportionally to community drawdowns in $\mathrm{CO}_{2}$, the assumption underlying our box model, our results suggest that the maximum potential local OA mitigation due to seagrass metabolism during daylight hours is similar across time and ecosystems, but small in magnitude.

We also demonstrate that seagrass beds are generally net autotrophic over the length of the day (based on daily NCP), and the magnitude of this full-day NCP is more pronounced during summer months and in tropical geographies (Fig 3C). However, underlying the summertime peak in full-day NCP is the potential for marked diurnal variability in $\mathrm{pH}$. In particular, the demonstrated summertime peak in hourly respiration rates could drive more pronounced nighttime lows in $\mathrm{pH} / \mathrm{saturation}$ state during the most pronounced windows for net autotrophy (i.e., summer months with the highest daily NCP). However, diurnal fluctuations in seawater $\mathrm{pH}$ associated with seagrass metabolism will also be influenced by hydrodynamics that are not captured in our synthesis (Koweek et al. 2018), and recent field studies of estuarine eelgrass by Ricart et al. (2021) demonstrated that sustained elevations in $\mathrm{pH}$ associated with seagrass meadows were not restricted to daylight hours. Regardless, a critical next step for understanding the utility of seagrass beds for climate adaptation is to determine how the demonstrated seasonal 
448 variability and the potential diurnal variability in carbonate chemistry are integrated over time by

449 organisms, especially under conditions projected for coastal habitats in the future.

450

451 Given the positive correlations between GPP and temperature, we assume that most of these

452 measurements were taken when the environmental temperatures were not physiologically

453 stressful to the seagrass community. Thus, the positive relationship between environmental

454 temperature and GPP should not necessarily be viewed through the lens of temperature

455 exposures associated with future warming driven by climate change. Continued warming

456 associated with climate change could cause photosynthesis and respiration to decline at stressful

457 temperatures. The probability that the relationship between temperature and metabolic responses

458 will change with future warming is likely to differ geographically based on how close a

459 community is to its thermal limit and the scope for acclimation or adaptation. This may partially

460 explain the differences in the relationships between temperature and the residuals of the seasonal

461 model between geographies, with increasing temperature negatively related to the residuals from

462 tropical geographies and positively related to the residuals from temperate geographies. Many

463 tropical seagrass species are growing close to their photosynthetic and physiological optima (Lee

464 et al. 2007, Koch et al. 2012), and elevated temperatures in these geographies may be

465 detrimental, causing metabolism (in this case hourly GPP) to be less than expected based on

466 seasonal patterns. In contrast, the positive relationship between the residuals from the seasonal

467 model and temperature in temperate geographies indicate that there may be a stimulatory effect

468 before a thermal tolerance threshold is crossed and metabolism decreases.

469 
470

471

472

473

474

475

476

477

478

479

480

481

482

483

484

485

486

487

488

489

490

491

492

The significant relationships between aboveground biomass and the residual variation in hourly GPP and NCP indicate that aboveground biomass also plays an important role in carbon fluxes beyond that which is already captured by any seasonal fluctuations in biomass. Although the relationships between aboveground biomass and the residual variation in hourly GPP are generally what would be expected (higher biomass = higher metabolic rates than expected based on the seasonal model), the negative relationship between aboveground biomass and the residual variation in hourly NCP is somewhat surprising. This relationship suggests that deployments/measurements in seagrass beds with higher aboveground biomass generally had lower hourly NCP than what is predicted by the seasonal model. This negative relationship may be explained by self-shading in dense meadows, or it could be due to other organisms that contribute to daytime respiration (e.g., heterotrophs) that are associated with the higher biomass meadows due to its structural complexity or other habitat features, but are not accounted for in the aboveground biomass measurements. Dedicated experiments may be able to determine the mechanism for these findings; however, the positive relationships between aboveground biomass and the residual variation in daily NCP suggests that, overall, higher aboveground biomass generally increases production relative to respiration.

\subsection{Implications for local OA mitigation and management}

The results of our steady state box model analyses illustrate the potential scope for seagrass NCP to influence seawater $\mathrm{pH}$ on an hourly basis (Fig. 6), with the change in $\mathrm{pH}$ being proportional to NCP during daylight hours and R during nighttime hours. While the box model is useful in making coarse estimates on what particular NCP values might correspond to in seawater $\mathrm{pH}$, it is important to note that it only represents a first step in translating the seagrass community 
493 metabolism estimates to seawater biogeochemistry. This is in part because the ratio of NCP

494 based on carbon fixed and oxygen evolved in seagrass communities is likely to be quite variable.

495 Although the ratio between $\mathrm{O}_{2}$ produced and carbon fixed by an individual seagrass is generally

496 assumed to be balanced (i.e., 1:1), the other processes that occur in a seagrass meadow, including

497 respiration from organisms living within the seagrass and carbonate production and dissolution,

498 also influence the dissolved inorganic carbon (DIC) concentration in the seawater. Current

499 empirical measurements of $\mathrm{NCP}_{\mathrm{DIC}}: \mathrm{NCP}_{\mathrm{O} 2}$ in seagrass meadows range from 0.3 to 6.8 (Ziegler

500 and Benner 1998, Barrón et al. 2006), suggesting the effect of seagrass NCP on seawater pH

501 could be substantially more or less pronounced than illustrated here. Because of this variability

502 in the relationship between $\mathrm{O}_{2}$ and DIC, care must be taken when interpreting the results from

503 the box model. A better understanding of the $\mathrm{NCP}_{\mathrm{DIC}}: \mathrm{NCP}_{\mathrm{O} 2}$ in particular meadows will better

504 inform their potential for local OA mitigation. Finally, the utility of seagrass as a climate

505 mitigation tool will depend on the goal of the management, and in most cases, will require more

506 research. For example, if the goal of management is to prevent negative effects of ocean

507 acidification on oyster growth, then studies that quantify the sensitivity of oyster growth to the

508 variability in $\mathrm{pH}$ observed here are still required.

509

5105 Conclusions

511 Few conservation or restoration efforts currently take into account the potential chemical

512 ecosystem services of seagrasses and other submerged aquatic vegetation. Here, we demonstrate

513 that daytime carbon fluxes associated with seagrass metabolism are likely to be similar across

514 seasons and geography, while the full-day carbon fluxes peak during summer months in both

515 tropical and temperate geographies. Integrating across seasons, seagrass meadows are net 
516

517

518

519

520

521

522

523

524

525

526

527

528

529

530

531

532

533

534

535

536

537

538

autotrophic. However, our simplified model results suggest the daytime carbon fluxes reported across the global ocean may translate to small changes in seawater $\mathrm{pH}$. These seasonal patterns largely capture the present-day effects of variability in temperature and aboveground biomass on seagrass metabolism, but likely do not adequately model the effects of future warming as it becomes physiologically stressful.

These results highlight challenges, as well as gaps in our understanding, that may impede the use of seagrasses for sustained local OA mitigation. In particular, we demonstrate that while peak daytime carbon fluxes are similar across seasons and geographies, nighttime respiration is highest during summer months. Thus, although seagrass beds are generally net autotrophic, nighttime respiration could reduce seawater $\mathrm{pH}$ during periods of greatest autotrophy. We provide examples of how water depth and residence time can influence the effect of seagrass on seawater $\mathrm{pH}$, and we demonstrate that the overall magnitude of the effect is likely quite small.

This work has elucidated several gaps that need to be addressed by the scientific community. For example, certain geographies, such as the North Pacific, are currently underrepresented in our dataset. Thus, continued study of seagrass metabolism and its effects on seawater carbonate chemistry are needed to expand our area of inference. In addition, studies are needed to constrain the relationship between dissolved oxygen fluxes and DIC, and this relationship may be important to elucidate at local scales to truly understand the potential for OA mitigation at a given location. Perhaps most importantly, more information is needed to understand how vulnerable organisms respond to the chemical variability highlighted in our study (Gimenez et al. 2018, Lowe et al. 2018), and in particular, how this variability is integrated through time. Despite 
539 the considerations of geographic and temporal variability in carbon fluxes illustrated here, we

540 recognize that seagrass conservation and restoration may be important strategies for climate

541 adaptation for numerous other reasons, including carbon sequestration and habitat provisioning.

542

543

6 Code Availability: Code is available at

544 https://github.com/tyekindinger/SeagrassCommunityMetabolism

545

5467 Data Availability: All data used in this analysis is publicly available via the published studies.

547

5488 Author Contributions: Kroeker: conceptualization, funding acquisition, investigation,

549 methodology, writing - original draft preparation; Kindinger: formal analysis, visualization,

550 writing - review \& editing; Hirsh: investigation, visualization, writing - review \& editing; Ward:

551 investigation, writing - review \& editing; Hill: conceptualization, funding acquisition, writing -

552 review \& editing; Jellison, Koweek, Lummis, Rivest, Waldbusser: conceptualization, writing -

553 review \& editing; Gaylord: conceptualization, funding acquisition, methodology, writing -

554 review \& editing.

555

5569 Competing Interests: The authors declare no competing interests

557

55810 Acknowledgments

559 We would like to thank K. J. Nickols and Y. Takeshita for their helpful comments and

560 suggestions, which greatly improved the manuscript. This work was initiated by a working group

561 of seagrass and biogeochemistry experts, convened at Bodega Marine Laboratory with support 
562 from California Sea Grant. The publication was prepared by K. J. Kroeker under NOAA Grant \#

563 NA14OAR4170075, California Sea Grant College Program Project \# R/HCME-03, through

564 NOAA'S National Sea Grant College Program, U.S. Dept. of Commerce. The statements,

565 findings, conclusions and recommendations are those of the author(s) and do not necessarily

566 reflect the views of California Sea Grant, NOAA or the U.S. Dept. of Commerce. In addition, K.

567 J. Kroeker and T. Kindinger received support from the David and Lucile Packard Foundation and

568 K. J. Kroeker received funding from the Alfred P. Sloan Foundation.

569

570

11 References

571 Agrawal, A., D. Nepstad, and A. Chhatre. Reducing emissions from deforestation and forest 572 degradation. Ann. Rev. Environ. Resour. 36:373-396, 2011.

573 Barrón, C., C. M. Duarte, M. Frankignoulle, and A. V. Borges. Organic carbon metabolism and 574 carbonate dynamics in a Mediterranean seagrass (Posidonia oceanica) meadow. Estuaries $575 \quad$ and Coasts 29:417-426, 2006

576 Bolker, B,. and D. Robinson. broom.mixed: Tidying Methods for Mixed Models. R package version 0.2.6. https://CRAN.R-project.org/package=broom.mixed, 2020.

Canadell, J. G., and M. R. Raupach. Managing forests for climate change mitigation. Science 320:1456-1457, 2008. 
585

586

587

588

589

590

591

592

593

594

595

596

597

598

599

600

601

602

603

604

605

606

607

Clavier, J., L. Chauvaud, E. Amice, P. Lazure, M. v. d. Geest, P. Labrosse, A. Diagne, A. Carlier, and S. Chauvaud. Benthic metabolism in shallow coastal ecosystems of the Banc d'Arguin, Mauritania. Marine Ecology Progress Series 501:11-23, 2014.

Cyronak, T., A. J. Andersson, S. D’Angelo, P. Bresnahan, C. Davidson, A. Griffin, T. Kindeberg, J. Pennise, Y. Takeshita, and M. White. Short-term spatial and temporal carbonate chemistry variability in two contrasting seagrass meadows: implications for $\mathrm{pH}$ buffering capacities. Estuaries and Coasts 41:1282-1296, 2018.

Duarte, C. M., and C. L. Chiscano. Seagrass biomass and production: a reassessment. Aquatic Botany 65:159-174, 1999.

Duarte, C. M., N. Marbà, E. Gacia, J. W. Fourqurean, J. Beggins, C. Barrón, and E. T. Apostolaki. Seagrass community metabolism: Assessing the carbon sink capacity of seagrass meadows. Global Biogeochemical Cycles 24:GB4032, 2010.

Gattuso, J. P., D. Allemand, and M. Frankignoulle. Photosynthesis and calcification at cellular, organismal, and community levels in coral reefs: A review on interactions and control by carbonate chemistry. Amer. Zool. 39:160-183, 1999.

Gimenez, I., G. G. Waldbusser, and B. Hales. Ocean acidification stress index for shellfish (OASIS): Linking Pacific oyster larval survival and exposure to variable carbonate chemistry regimes. Elem Sci Anth 6, 2018.

Hendriks, I. E., Y. S. Olsen, L. Ramajo, L. Basso, A. Steckbauer, T. S. Moore, J. Howard, and C. M. Duarte. Photosynthetic activity buffers ocean acidification in seagrass meadows. BIOGEOSCIENCES 11:333-346, 2014.

Herbert, D.A. and J.W. Fourqurean. 2008. Ecosystem structure and function still altered two decades after short-term fertilization of a seagrass meadow. Ecosystems 11: 688-700. 
608

609

610

611

612

613

614

615

616

617

618

619

620

621

622

623

624

625

626

627

628

629

630

James, R. K., M. M. van Katwijk, B. I. van Tussenbroek, T. van der Heide, H. A. Dijkstra, R. M. van Westen, J. D. Pietrzak, A. S. Candy, R. Klees, R. E. M. Riva, C. D. Slobbe, C. A. Katsman, P. M. J. Herman, and T. J. Bouma. Water motion and vegetation control the $\mathrm{pH}$ dynamics in seagrass-dominated bays. Limnology and Oceanography 65: 349-362, 2020.

Koch, M., G. Bowes, C. Ross, and X.-H. Zhang. Marine macro-autotrophs and climate change. Global Change Biology 19:103-132, 2012.

Koweek, D. A., R. C. Zimmerman, K. M. Hewett, B. Gaylord, S. N. Giddings, K. J. Nickols, J. L. Ruesink, J. J. Stachowicz, Y. Takeshita, and K. Caldeira. Expected limits on the ocean acidification buffering potential of a temperate seagrass meadow. Ecological Applications 28:1694-1714, 2018.

Kroeker, K. J., R. L. Kordas, R. N. Crim, and G. G. Singh. Meta-analysis reveals negative yet variable effects of ocean acidification on marine organisms. Ecology Letters 13:1419$1434,2010$.

Lowe, A. T., J. Kobelt, M. Horwith, and J. Ruesink. Ability of eelgrass to alter oyster growth and physiology is spatially limited and offset by increasing predation risk. Estuaries and Coasts 42:743-754, 2019.

Maher, D., and B. D. Eyre. Benthic carbon metabolism in southeast Australian estuaries: habitat importance, driving forces, and application of artificial neural network models. Marine Ecology Progress Series 439:97-115, 2011.

Manzello, D. P., I. C. Enochs, N. Melo, D. K. Gledhill, and E. M. Johns. Ocean acidification refugia of the Florida Reef Tract. PloS one 7:e41715., 2011.

Mcleod, E., G. L. Chmura, S. Bouillon, R. Salm, M. Björk, C. M. Duarte, C. E. Lovelock, W. H. Schlesinger, and B. R. Silliman. A blueprint for blue carbon: toward an improved 
631

632

633

634

635

636

637

638

639

640

641

642

643

644

645

646

647

648

649

650

651

652

653

understanding of the role of vegetated coastal habitats in sequestering $\mathrm{CO}_{2}$. Frontiers in Ecology and the Environment 9:552-560, 2011.

Nahlik, A. M., and M. S. Fennessy. Carbon storage in US wetlands. Nature Communications 7:13835, 2016.

Nielsen, K., J. Stachowicz, H. Carter, K. Boyer, M. Bracken, F. Chan, F. Chavez, K. Hovel, M. Kent, K. Nickols, J. Ruesink, J. Tyburczy, and S. Wheeler. Emerging understanding of the potential role of seagrass and kelp as an ocean acidification management tool in California. Oakland, California, USA, 2018.

Odum, E. Primary production in flowing waters. Limnology and Oceanography 1:102-117, 1956.

Odum, H. T., P. R. Burkholder, and J. Rivero. Measurements of productivity of turtle grass flats, reefs, and the Bahia fosforenscente of southern Puerto Rico. Publ. Inst. Mar. Sci 6:159$170,1959$.

Pacella, S. R., C. A. Brown, G. G. Waldbusser, R. G. Labiosa, and B. Hales. Seagrass habitat metabolism increases short-term extremes and long-term offset of $\mathrm{CO}_{2}$ under future ocean acidification. Proc. Natl. Acad Sci USA 115:3870-3875, 2018.

Pinheiro, J., D. Bates, S. DebRoy, D. Sarkar, and R Core Team. nlme: Linear and Nonlinear Mixed Effects Models. R package version 3.1-145, https://CRAN.Rproject.org/package=nlme, 2020.

R Core Team. R: A language and environment for statistical computing. R Foundation for Statistical Computing, Vienna, Austria. https://www.R-project.org/, 2019.

Rheuban, J. E., P. Berg, and K. J. McGlathery. Multiple timescale processes drive ecosystem metabolism in eelgrass (Zostera marina) meadows. Marine Ecology Progress Series 507:1-13, 2014. 
654 Ricart, A. M., M. Ward, T. M. Hill, E. Sanford, K. J. Kroeker, Y. Takeshita, S. Merolla, P.

655

656

657

658

659

660

661

662

663

664

665

666

667

668

669
Shukla, A. Ninokawa, K. Elsmore and B.P. Gaylord. Coast-wide evidence of low pH amelioration by seagrass ecosystems. Global Change Biology, 27: 2580-2591, 2021.

Robinson, D., A. Hayes, and S. Couch. broom: Convert Statistical Objects into Tidy Tibbles. R package version 0.7.3. https://CRAN.R-project.org/package=broom, 2020.

UNEP-WCMC and F. T. Short. Global distribution of seagrasses (version 6.0). Sixth update to the data layer used in Green and Short (2003). Cambridge (UK): UN Environment World Conservation Monitoring Centre. URL: http://data.unep-wcmc.org/datasets/7, 2018.

Unsworth, R. K. F., C. J. Collier, G. M. Henderson, and L. J. McKenzie. Tropical seagrass meadows modify seawater carbon chemistry: implications for coral reefs impacted by ocean acidification. Environ. Res. Lett. 7:024026, 2012.

Washington State Blue Ribbon Panel on Ocean Acidification. Ocean Acidification: From Knowledge to Action, Washington State's Strategic Response. Publication no. 12-01015., Olympia, Washington, 2012.

Ziegler, S., and R. Benner. Ecosystem metabolism in a subtropical, seagrass-dominated meadow. Marine Ecology Progress Series 173:1-12, 1998. 